\title{
IATROGENIC CUSHING SYNDROME AND ADRENOCORTICAL INSUFFICIENCY FROM TOPICAL STEROIDS IN A GIRL WITH NETHERTON SYNDROME - CASE REPORT
}

\author{
Lena KOTRULJA ${ }^{1 *}$, Suzana OŽANIĆ BULIĆ ${ }^{2}$, Zora ZAKANJ $^{3}$, Lavinia LA GRASTA SABOLIĆ ${ }^{4}$
}

\begin{abstract}
${ }^{1}$ Clinic for Dermatology and venereology DermaPlus Zagreb, Coratia, ${ }^{2}$ University Hospital Centre "Sestre milosrdnice", Department of Dermatology and venereology, Zagreb, Coratia, ${ }^{3}$ Clinical Hospital "Sveti Duh", Department of Neonatology, Zagreb Croatia, ${ }^{4}$ University Hospital Centre "Sestre milosrdnice”, Department of Paediatric Edocrinology Zagreb, Croatia
\end{abstract}

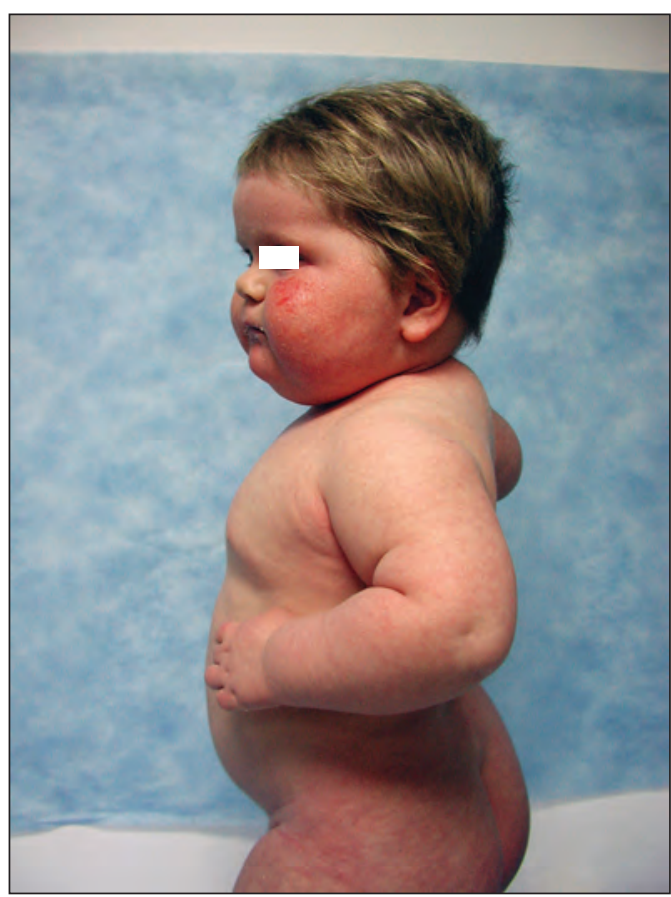

Fig 1. Iatrogenic Cushing syndrome in a child with Netherton syndrome treated with herbal cream containing highly potent topical steroid.

Netherton syndrome (NS) is a rare, autosomal recessive genetic disorder associated with decreased skin barrier function. NS is characterized by ichthyosiform erythroder- ma, hair shaft abnormalities, and atopic diathesis. Infants exposed to prolonged topical corticosteroids application have greater risk for iatrogenic Cushing syndrome caused by suppression of the hypothalamic-pituitaryadrenal axis (HPA) with subsequent adrenocortical insufficiency following topical treatment withdrawal. We report a-three-year old girl with NS who was incidentally treated with potent topical corticosteroid cream purchased from herbalist over six months for whole skincare (Fig. 1). Because of percutaneous systemic corticosteroid absorption she developed iatrogenic Cushing syndrome with secondary adrenal failure. Genetic diagnosis of NS was performed by PCR amplification of complete coding region and adjacent intron/exon boundaries specific for the SPINK 5 gene. Two heterozygous mutations were detected in exon 5 and 8 of SPINK gene. Iatrogenic Cushing syndrome was suspected based on clinical presentation (cushingoid appearance with moon face, centripetal obesity, buffalo hump, and purple striae), height for age -3.1 SDS, centripetal obesity with BMI for age +3.7 SDS) and confirmed by low morning levels of cortisol $(2.0 \mathrm{nmol} / \mathrm{l})$ and ACTH (2.8 pmol/l). Electrolytes were within normal limits and plasma glucose was low $(2.8 \mathrm{mmol} / \mathrm{l})$. Hydrocortisone (Cortef) $13 \mathrm{mg} / \mathrm{m}^{2} /$ day was introduced by the endocrinologist with slow taper of the dose over 10 months, with complete HPA axis recovery. The parents and physicians should be 
warned about the use of even low potency steroid cream in all children with decreased skin barrier function and increased percutaneous absorption having increased risk of HPA suppression.

Key words: Cushing syndrome - Netherton syndrome - Topical steroids.

Authors' contributions: Conception and design: LK; Acquisition, analysis and interpretation of data: LK,
SOB, LDS, ZZ; Drafting and revising the article: SOB, LK; Revising it critically for important intellectual content: LK, LGS, ZZ, SOB.

Conflict of interest: The authors declare that they have no conflict of interest.

${ }^{*}$ Corresponding author: lena.kotrulja@dermaplus.hr

Tel.: + 38514819 504; Fax.: + 38514819555

Received: May 23, 2015; Accepted: August 24, 2015 